\title{
Consequences of $\mathrm{MgO}$ activation procedures on its catalytic performance for acetone self-condensation
}

M. León ${ }^{1,2}$, L. Faba ${ }^{1,2}$, E. Díaz ${ }^{1}$, S. Bennici ${ }^{2}$, A. Vega ${ }^{1}$, S. Ordóñez ${ }^{1}$, A. Auroux ${ }^{2}$

1. Department of Chemical and EnvironmentalEngineering, University of Oviedo, JuliánClavería s/n, E-33006 Oviedo, Spain

2. Université Lyon 1, CNRS, UMR 5256, IRCELYON, Institut de Recherches sur la Catalyse et l'Environnement de Lyon, 2 avenue Albert Einstein, F69626Villeurbanne, France e-mail:sordonez@uniovi.es,Tel: +34 985103 437; Fax:+ 34985103434 


\begin{abstract}
A new procedure for increasing surface area and basicity of $\mathrm{MgO}$ has been developed in this work, leading to a tailored catalyst for the self-condensation of acetone. The preparation method, consisting on the hydration/dehydration of periclase, was optimized varying theactivation procedures. The effect of the precursor (magnesium oxide or magnesium carbonate) and the thermal treatment on the morphological properties and the basic sites distribution was characterised.In particular, $\mathrm{CO}_{2}$ calorimetry data attributed the increase of basic sites mainly to the increase in surface area. Thematerial was tested for the base-catalyzedself-condensation ofacetone, obtaining high conversions and selectivities towards the products of most industrial value, the isophorones. The selectivity reached to trimers at $723 \mathrm{~K}$ was almost $50 \%$, and towards isophorones, of more than $30 \%$.
\end{abstract}

Keywords: basic materials;brucite-periclase transitions; $\mathrm{CO}_{2}$ adsorption; hydromagnesite; acetone condensation; biomass upgrading 


\section{INTRODUCTION}

Basecatalysis plays a key role in the upgrading of biomass-derived platform molecules. Several base-catalysed reactions, such as ketonic or aldol condensations, lead to concurrent carbon chain growth and oxygen removal of oxygenates [1]. Aldol condensation consists of the condensation of molecules with two carbonyl groups yielding hydroxyl-ketones or unsaturated ketones [2], and it is a key reaction for biomass feedstock upgrading [3]. Among the reactants that can undergo this reaction, an increasing attention is being paid to acetone. In fact, although acetone is nowadays mainly produced from fossil stocks, new technologies based on chemical and biological processes are emerging: biomass pyrolysis [4] or the $\mathrm{ABE}$ fermentation of agricultural wastes [5]. Thus, acetone self-condensation becomes in an interesting reaction for obtaining chemicals by itself (mainly isophorones) or in combination with hydrogenation steps (methyl-isobutyl ketone, MIBK).

Gas phase self-condensation of acetone yields to isophorones (cyclic trimers) as the most valuable product, with applications in paints, pesticides, adhesives, resins, etc., whereas liquid phase condensations (usually performed in presence of $\mathrm{H}_{2}$ ) are mainly devoted to manufacturing methyl-isobutyl ketone (MIBK).Different basic catalysts have been proposed for this condensation, such as niobium oxides [6], Mg-Al mixed oxides [7,8], Mg-Zr mixed oxides and Mg-Zr oxides dispersed on carbonaceous materials to increase the exposed surface area [9] and even $\mathrm{MgO}$,non-promoted and promoted with alkaline or alkaline-earth metal ions [10]. Among all these catalysts, bulkMgO is the cheapest alternative and very attractive due to its preparation easiness. However, magnesium oxide presents an important drawback in comparison to other common catalysts, its low surface area. Furthermore, the selectivity towards isophorones is 
reduced in comparison to, for example, $\mathrm{Li} / \mathrm{MgO}[10]$. This effect was attributed to the low concentration of high-strength basic sites in the non-promoted catalyst.

Commercial $\mathrm{MgO}$ has low surface areas (typically, around $20 \mathrm{~m}^{2} / \mathrm{g}$ ) and also low concentration of basic sites (around $0.4 \mathrm{mmol} / \mathrm{g}$ ). Consequently, many methodologies for the synthesis of $\mathrm{MgO}$ with high surface area and higher concentration of exposed basic sites have been developed. Bhagiyalakshmiet al. [11] reported a method for synthesizing mesoporous magnesium oxide from a commercial $\mathrm{MgO}$ that enhances the specific surface area of the starting material up to $250 \mathrm{~m}^{2} / \mathrm{g}$. In addition, the $\mathrm{CO}_{2}$ adsorption capacity, an indicator of the surface basicity, increases from 0.45 to 2.3 $\mathrm{mmol} / \mathrm{g}$ at $373 \mathrm{~K}$, being this value the highest ever reported for magnesium oxide. The drawback of the aforementioned preparation method stems from its complexity, since it requires the synthesis of SBA-15 and CMK-3, which involves steps as pyrolysis at 1173 $\mathrm{K}$ and the use of acids such as sulfuric or hydrofluoric. Other synthesis method proposed is the sol-gel $[12,13]$, which involves a multi-step decomposition process of a precursor in the presence of an expensive template. Surface areas in the range of 250$650 \mathrm{~m}^{2} / \mathrm{g}$ have been reached [14], although the template should be removed in subsequent steps. In an attempt to avoid the use of templates and toxic solvents, Bian et al. [15] described a procedure to synthesize mesoporousMgO with a nanocrystalline framework via the thermal decomposition of magnesium acetate, obtaining surface areas around $120-136 \mathrm{~m}^{2} / \mathrm{g}$. Another important synthetic route for the preparation of high surface area $\mathrm{MgO}$ involves thermal treatment of $\mathrm{Mg}(\mathrm{OH})_{2}$, obtained either by precipitation or by $\mathrm{MgO}$ hydration, leading to surface areas ranging 100-300 $\mathrm{m}^{2} / \mathrm{g}$ [14]. This method is remarkable for its simplicity and reduced cost, which makes the MgOso formed a plausible inexpensive catalyst. Furthermore, in a recent work, Bartley et al. 
[16] have obtained a high surface area $\mathrm{MgO}$ by thermal procedures with different morphologies and surface properties depending on the precursor and thermal conditions.

In the present work, the thermal treatment method will be considered according to its proven compromise between surface area enhancement and environmental benignity. Two precursors were used for the preparation of $\mathrm{Mg}(\mathrm{OH})_{2}$, namely, commercial $\mathrm{MgO}$ and $\mathrm{MgCO}_{3}$. Their thermal decomposition (temperature and time) into the final $\mathrm{MgO}$ was optimized taking into account the $\mathrm{CO}_{2}$ adsorption capacity,as measurement of both their surface basicity and potential as $\mathrm{CO}_{2}$ adsorbents. Morphological aspects of the catalysts were characterized by temperature-programmed XRD and $\mathrm{N}_{2}$ physisorption. Since $\mathrm{Mg}(\mathrm{OH})_{2}$ dehydration is believed to be a key step, transitions brucite-periclase were analyzed in detail by means of XRD scans recorded at increasing temperatures, as well as a function of time at the decomposition temperature. The number and strength of surface basic sites on the catalysts were studied by microcalorimetry andFTIR. Finally, the gas phase acetone condensation was used as model reaction of basic catalyst. It is shown that a simple catalyst with an appropriate morphology and high concentration of basic sites can be obtained.

\section{MATERIALS AND METHODS}

\section{1. Materials preparation}

Increased surface area magnesium oxides were prepared from two different precursors, namely: commercial magnesium oxide (Panreac) and magnesium carbonate (Fluka). Magnesium carbonate was firstly decomposed into magnesium oxide by thermal treatment in a tubular (23 mm i.d.) fixed bed reactor from room temperature to $973 \mathrm{~K}$ at 
a rate of $5 \mathrm{~K} / \mathrm{min}$ and then maintained the final temperature for $3 \mathrm{~h}$ under synthetic air flow (in order to ensure the absence of $\mathrm{CO}_{2}$ and water). Both magnesium oxides commercial precursor and obtained from decomposition of magnesium carbonate- were converted into magnesium hydroxide by slow addition of distilled water at room temperature under stirring, in the ratio of $10 \mathrm{~mL}$ of water per gram of magnesium oxide, according to the procedure outlined in[10]. The temperature was subsequently raised to $353 \mathrm{~K}$ and stirring was maintained for $4 \mathrm{~h}$. Finally, the precipitate was dried overnight in an oven at $358 \mathrm{~K}$. Magnesium oxide was re-synthetized by thermal decomposition of magnesium hydroxideunder air flow in two steps: sample was first treated at $623 \mathrm{~K}$ for $5 \mathrm{~h}$ and then at $773 \mathrm{~K}$ during $8 \mathrm{~h}$. Thetemperature programme for the decomposition of $\mathrm{Mg}(\mathrm{OH})_{2}$ was optimized targeting the largest $\mathrm{CO}_{2}$ uptake.For that, analogous analyses were performed using a thermogravimetry-differential scanning calorimetry (TG-DSC) instrument (Setaram, Sensys).

Samples considered in the present work were designed as follows: $\mathrm{MgO}(\mathrm{I})$ for the commercial magnesium oxide, $\mathrm{MgO}$ (II) for the magnesium oxide obtained from decomposition of the magnesium carbonate, and hsMgO(I) and hsMgO(II) for the samples resulting after the hydration and thermal treatment from $\mathrm{MgO}(\mathrm{I})$ and $\mathrm{MgO}(\mathrm{II})$, respectively (Scheme 1).

\section{2. Materials characterization}

The textural properties of the samples were determined by $\mathrm{N}_{2}$ adsorption-desorption isotherms at $77 \mathrm{~K}$ in a Micromeritics ASAP 2020. Prior to the analysis, the samples were outgassed at vacuum conditions $\left(<10^{-3} \mathrm{kPa}\right)$ at $473 \mathrm{~K}$ for $4 \mathrm{~h}$. The surface area $\left(\mathrm{S}_{\mathrm{BET}}\right)$ was calculated according to the Brunauer-Emmett-Teller (BET) method, whereas 
the pore size distributions and total pore volumes $\left(\mathrm{V}_{\mathrm{P}}\right)$, corresponding to the cumulative pore volumes between 170 and $30000 \mathrm{~nm}$, were determined from the desorption branch using the Barrett-Joyner-Halenda $(\mathrm{BJH})$ method. Analysis by scanning electron microscopy(SEM) was done using a JeolJSM-6100 microscope; the samples were deposited on a standard aluminium SEM holder andgold-coated.

The crystalline structure of the samples was studied by XRD using a Philips X'Pert Pro powder diffractometer equipped with a $\mathrm{CuK} \alpha$ radiation source $(0.15418 \mathrm{~nm})$ and operating in a $2 \theta$ range of $5-85^{\circ}$ at a scanning rate of $0.02 \%$. The X-ray tube voltage and current were set at $45 \mathrm{kV}$ and $40 \mathrm{~mA}$, respectively. Additional XRD experiments were carried out in a Seifert XRD 3000 diffractometer, which is equipped with a temperature controlled chamber, in order to follow the brucite-periclase transition. Magnesium hydroxide samples were subjected to a temperature programme from 298 up to $773 \mathrm{~K}$ at a heating rate of $5 \mathrm{~K} / \mathrm{min}$, while 25 scans were recorded. Once determined the transition temperature, the evolution of the structure with time at that constant temperature was studied by recording 30 consecutive scans onfresh hydroxidesamples. The equipment settings were analogous to the above described.

\section{3. $\mathrm{CO}_{2}$ adsorption}

In order to quantitatively establish the $\mathrm{CO}_{2}$ adsorption capacity, and consequently the total concentration of basic sites, calorimetric experiments were carried out in a TianCalvetmicrocalorimeter (C80, Setaram) linked to a volumetric line. The adsorption of $\mathrm{CO}_{2}$ took place by repeatedly introducing small doses of gas onto the initially outgassed solid until a final equilibrium pressure of $6.7 \mathrm{kPa}$. Before adsorption, about $80 \mathrm{mg}$ of sample were outgassed overnight at $623 \mathrm{~K}$ under vacuum $\left(10^{-6} \mathrm{kPa}\right)$. The equilibrium 
pressure was measured after each dose by a Barocel Capacitance Manometer (Datametrics). The adsorption temperature was maintained at a constant value.

In order to gain further understanding on the strength of the surface basic sites, the chemical structure of the chemisorbed $\mathrm{CO}_{2}$ was characterised by Fourier Transform Infrared Spectroscopy (FT-IR). Data were obtained using a Bruker Vector 22 FT-IR spectrophotometer (DTGS detector), in the 4000-400 $\mathrm{cm}^{-1}$ range, with a resolution of 2 $\mathrm{cm}^{-1}$ and using 100 scans. An inverted T-shaped Pyrex cell containing the sample pellet was used. The two ends of the short arm of the $\mathrm{T}$ were fitted with $\mathrm{CaF}_{2}$ windows. The self-supporting wafer ( $20 \mathrm{mg}, 18 \mathrm{~mm}$ diameter) was first pre-treated in situ at $573 \mathrm{~K}$ in an oxygen flow overnight in order to remove surface substances, then evacuated at the same temperature for $2 \mathrm{~h}$ and finally exposed to $\mathrm{CO}_{2}(1 \mathrm{kPa})$ at room temperature for 5 min. Spectra were taken at room temperature after $\mathrm{CO}_{2}$ adsorption and sequential evacuation for $20 \mathrm{~min}$ at room temperature, 323, 373, 473, 573, and $673 \mathrm{~K}$. The background spectrum was measured before adsorption and used to correct the others spectra by absorbance subtraction.

\subsection{Reaction studies}

The reaction was performed in a $0.4 \mathrm{~cm}$ i.d. U-shaped fixed bed quartz reactor placed in a PIDcontrolled electric furnace. The catalyst $(150 \mathrm{mg}, 50-80 \mu \mathrm{m})$ was placed over a plug of quartz wool and a thermocouple was placed inside the catalyst bed. A gas flow of $0.05 \mathrm{~L} \cdot \mathrm{min}^{-1}$ (s.t.p.) of helium- acetone mixture (3.2 vol\%acetone)was fed. Acetone was injected as a liquid by a syringe pump in a He flow and vaporized in situ.Reactor outgoing gases were analyzed on-line by gas chromatography using a HP6890 GC, equipped with a FID detector and using a CP-Sil 5 CB capillary column as stationary phase. Product identification was confirmed by analysis in a 
GC-MS (Shimadzu QP-2010), using the same column and conditions that in the gas

chromatograph.

Conversions were calculated from the acetone concentration at the reactor inlet and outlet, whereas selectivities were calculated as the ratio between the concentration of each reaction product and the sum of the concentration of all the reaction products. Carbon balance was checked by comparing the total amount of carbon atoms at the reactor inlet and outlet.

\section{RESULTS AND DISCUSSION}

\subsection{Materials characterisation}

\subsubsection{Crystallographic characterisation}

X-Ray diffraction patterns of the samples, Fig. 1, showed the typical diffractograms ofpericlase (JCPDS 45-946), with peaks at $\sim 37^{\circ}, 43^{\circ}, 62^{\circ}, 75^{\circ}$ and $79^{\circ}$, which correspond to diffraction by planes (111), (200), (220), (311) and (222), respectively. Phases corresponding to the precursors were not detected. Sample $\mathrm{MgO}(\mathrm{I})$, the commercial magnesium oxide, presented peaks considerably sharper and more intense, indicating a markedly more developed crystallinity, which is in agreement with the considerable lower specific surface area exhibited by this sample. The crystallite size of the magnesium oxides calculated from the plane (200) using the Debye-Scherrer equation[17] areincluded in Table 1.

Brucite-periclasetransitions were studied by temperature-programmed XRD, being the diffractograms recorded at different temperatures depicted in Fig. 2.The diffractograms recorded at $298 \mathrm{~K}$ correspond to the magnesium hydroxides obtained from the parent magnesium oxides. In the case of magnesium hydroxide resulting from $\mathrm{MgO}$ (I) (Fig. 2a), the peaks at $\sim 19^{\circ}, 33^{\circ}, 38^{\circ}, 51^{\circ}, 59^{\circ}, 62^{\circ}, 68^{\circ}, 72^{\circ}$ and $81^{\circ}$ are characteristic of 
brucite phase (JCPDS 7-239) and are related to planes (001), (100),(101),(102),(110),(111),(103),(201) and (202), respectively. Nevertheless, in the diffraction pattern corresponding to the sample obtained from hydration of $\mathrm{MgO}$ (II) (Fig. 2b), the presence of a second phase, hydromagnesite $\left(\mathrm{Mg}_{5}\left(\mathrm{CO}_{3}\right)_{4}(\mathrm{OH})_{2} \cdot 4 \mathrm{H}_{2} \mathrm{O}\right)$ is evidenced. This phase is unambiguously identified according to the peaks at $\sim 10^{\circ}, 14^{\circ}$, $15^{\circ}, 20^{\circ}, 21^{\circ}, 23^{\circ}, 25^{\circ}, 27^{\circ}, 28^{\circ}, 31^{\circ}, 33^{\circ}, 36^{\circ}, 41^{\circ}, 42^{\circ}$ and $45^{\circ}$, which correspond to diffraction by planes (100), (-110), (011), (020), (-102), (002), (012), (-221), (211), (310), (-321), (230), (023), (113) and (-423), respectively (JCPDS 25-513). This phase is supposed to remain from magnesium carbonate used as precursor. From Fig. 2b, hydromagnesite vanished above $566 \mathrm{~K}$, giving rise to a sole phase of brucite. In both cases, the increase in temperature led to a transition from brucite to periclase, which was patent above $608 \mathrm{~K}$. With the aim of studying the kinetic underlying the phase transition, additional sets of scans were recorded at $608 \mathrm{~K}$ at increasing times. A first order kinetics was established for the transformation of brucite into periclase from the decrease with time of the peaks at $38^{\circ}$, assumed proportional to the concentration of brucite phase in the sample. Thekinetic data are summarized in Fig. 3, were the natural logarithm of the ratio between the area under the peak at a given time, and this area at initial time is plotted versus time. Thekinetic constant, obtained from the slope of the line, for sample $\mathrm{I}\left(\mathrm{k}_{\mathrm{I}}=6.8 \cdot 10^{-4} \mathrm{~s}^{-1}\right)$ was found to be more than twice the value of the constant for sample II $\left(\mathrm{k}_{\mathrm{II}}=3.0 \cdot 10^{-4} \mathrm{~s}^{-1}\right)$, which is consistent with the fact that the complete transition was reached in half of the time for sample I. Thus, dehydroxylationis favoured in the pure magnesium oxide, whereas the carbonate remaining in the $\mathrm{MgO}$ (II) sample hinders the process, decreasing in this way its transformation velocity. The higher transformation rate observed for sample $\mathrm{MgO}$ (I) 
alsolead to the formation of metastable species and larger amount of crystalline defects [19], usually considered as responsible of basic sites.

\subsubsection{Morphological characterisation}

Adsorption isotherms for the magnesium oxides considered in the present workare shown in Fig. 4, whereas the textural properties of the samples are summarized in Table 1. With the exception of $\mathrm{MgO}(\mathrm{I})$, which exhibits an isotherm type II, the other isotherms correspond to the type IV (mesoporous solids), according to the IUPAC classification. The hysteresis loops are rather narrow and, in the case of hsMgO(I) and hsMgO(II), vertically oriented; whereas for $\mathrm{MgO}(\mathrm{II})$, it remains nearly horizontal and parallel over a wide range of $\mathrm{p} / \mathrm{p}^{0}$, suggesting a change toward a slit-shaped porosity upon activation. In the case of $\mathrm{MgO}(\mathrm{I})$, the slight hysteresis loop could correspond to condensation of adsorbate in interparticlemacropores.

Comparing the samples obtained after hydration and thermal treatment with their respective precursors, an increase in the specific surface area can be appreciated, as well as in the pore volume, being especially significant in the case of the commercial sample, where the treatment leads to a development of the BET surface area from 26 to 221 $\mathrm{m}^{2} / \mathrm{g}$ and of the pore volume, reaching $1.15 \mathrm{~cm}^{3} / \mathrm{g}$. Evacuation of water formed as a product of $\mathrm{Mg}(\mathrm{OH})_{2}$ decomposition could be the responsible of these expansion in the structure.

SEM images of the samples under study are shown in Fig. 5. It is observed that $\mathrm{MgO}(\mathrm{I})$ and $\mathrm{MgO}(\mathrm{II})$ exhibit a compact structure, especially in the case of $\mathrm{MgO}(\mathrm{I})$. On the contrary, hsMgO samples present a more spongy morphology. All these facts are in agreement with surface area measurements, since hsMgO(I) presents the highest $\mathrm{S}_{\mathrm{BET}}$. 
This high surface area of hsMgO(I) sample can be also explained according to its crystallographic transformation.It was reported that in the formation of periclase, bydehydroxylationof brucite, structural oxygen vacancies are formed by the removal ofwater [19]. This generation of structural defectsbecomes more important when the process is faster. Accordingly, hs $\mathrm{MgO}(\mathrm{I})$ sample should have a higher amount of morphological irregularities and therefore a larger surface area of .

\subsection{Surface chemistry}

\subsubsection{Calorimetric studies of $\mathrm{CO}_{2}$ adsorption}

Equilibrium adsorption isotherms at $0-6.7 \mathrm{kPa}$ and $323 \mathrm{~K}$ were recorded by microcalorimetry, Fig. 6 . The shape of these curves suggests the presence of combined chemisorption and physisorption mechanisms.It can be noticed that a larger uptake of $\mathrm{CO}_{2}$ was reached by sample hsMgO(I) $-1.2 \mathrm{mmol} / \mathrm{g}(52.8 \mathrm{mg} / \mathrm{g})-$, followed by hsMgO(II) $-0.82 \mathrm{mmol} / \mathrm{g}(36.1 \mathrm{mg} / \mathrm{g})-$, confirming the suitability of the modification method. These values of capacity of adsorption are similar to $\mathrm{Mg}$-Al mixed oxides used also in aldol condensation reactions [20], and considerable higher than zirconia catalysts doped with sodium, used in the ethanol coupling to 1-butanol reaction [21]. Considering the adsorption capacities in surface area basis $\left(5.4 \mu \mathrm{mol} / \mathrm{m}^{2}\right.$ for hsMgO (I) vs. 9.4 for hsMgO(II)), it is clear that the higher global concentration of basic sites in sample hsMgO (I) is mainly caused by the increase of the surface area.

Adsorption microcalorimetry is a very useful technique for the characterization of basic properties of solids, not only the basic sitesconcentration but also their strengthdistribution [22]. From the distribution of basic sites (Fig. 7), heterogeneity of 
the strength of the basic sitesis observed. These sites can be separated in three groups according to their strength: strong $(\mathrm{Q}>150 \mathrm{~kJ} / \mathrm{mol})$, medium $(120 \mathrm{~kJ} / \mathrm{mol}<\mathrm{Q}<150$ $\mathrm{kJ} / \mathrm{mol})$ and weak $(\mathrm{Q}<90 \mathrm{~kJ} / \mathrm{mol})[23,24]$. Fig. 7 also shows the distribution of the strength of the basic sites. It is noticed that $\mathrm{MgO}(\mathrm{I})$ and $\mathrm{hsMgO}(\mathrm{I})$ do not present the strongest sites, contrary to the samples obtained from magnesium carbonate. The fast transformation of brucite into periclase would hinder the formation of the strongest basic sites.These observations are in agreement with the kinetic of the $\mathrm{CO}_{2}$ desorption studied for hsMgO(I) and hsMgO(II) by TPD profiles obtained by thermogravimetry [18]. Deconvolution of the curve revealed two adsorption sites for hsMgO(I), with activation energies of desorption of 56 and $111 \mathrm{~kJ} / \mathrm{mol}$; and three for hsMgO(II), with activation energies of desorption of 62,85 and $142 \mathrm{~kJ} / \mathrm{mol}$ [18]. The adsorption sites with activation energies lower than $150 \mathrm{~kJ} / \mathrm{mol}$ were already observed in magnesium derived oxides, more concretely $\mathrm{Mg}-\mathrm{Al}$ and $\mathrm{Mg}-\mathrm{Fe}$ mixed oxides [20,25].

\subsubsection{Spectroscopic characterisation of the adsorbed species (FTIR)}

In order to get further information about the basic sites of the magnesium oxides, infrared spectroscopic studies of the surface of the samples after $\mathrm{CO}_{2}$ adsorption and desorption at temperatures up to $673 \mathrm{~K}$ were performed (Fig. S1). Analysis of the spectra provides useful information on the nature of the species formed upon $\mathrm{CO}_{2}$ adsorption, complementing the conclusions drawn from microcalorimetry about the strength and relative amount of basic sites.

FTIR spectra in the $900-1900 \mathrm{~cm}^{-1}$ region of the samples after $\mathrm{CO}_{2}$ adsorption at room temperature, and subsequent desorption under vacuum at temperatures up to $673 \mathrm{~K}$ were recorded. Computer decomposition of the spectra, evaluation of the resistance to 
evacuation and the spectral parameter $\Delta v_{3}$, have been used for the assignation of the species modes. The splitting, $\Delta v_{3}$, can be considered as a measure of the strength of the base sites: the lower the splitting, the stronger the basic site[12]. For $\Delta v_{3}$ values of about 100,300 and $400 \mathrm{~cm}^{-1}$ are generally proposed for unidentate, chelating bidentate and bridging bidentate structures, respectively [26].Unidentate species are formed on oxygen ions showing the lowest coordination number $\left(\mathrm{O}^{2-}\right.$, strong base sites $)$, whereas chelating and bridging bidentate carbonates require the participation of an adjacent cationic site ( $\mathrm{M}^{\mathrm{n+}}-\mathrm{O}^{2-}$ pairs, medium strength base sites) [27] (Scheme 2).

Table 2 summarizes the assigned bands for each species in the four samples after $\mathrm{CO}_{2}$ adsorption at room temperature, as well as the area of the decomposed peaks corresponding to each species, which is proportional to the concentration of each type of basic site present in the samples, and the $\Delta v_{3}$ values. Bands at around 1685, 1460 and $1220 \mathrm{~cm}^{-1}$ can be assigned to asymmetric O-C-O stretching vibration (asymv $v_{\mathrm{O}-\mathrm{C}-\mathrm{O}}$ ), symmetric O-C-O stretching vibration (symv $\left.v_{\mathrm{O}-\mathrm{C}-\mathrm{O}}\right)$ and $\mathrm{C}-\mathrm{OH}$ bending mode $\left(\delta_{\mathrm{COH}}\right)$, respectively, of bicarbonate. Pairs of bands at 1633-1640 (asymv $\left.v_{\mathrm{O}-\mathrm{C}-\mathrm{O}}\right) / 1381-1386$ $\left(\right.$ symv $\left._{\text {O-C-O }}\right), 1590-1603$ (asymv $\left.v_{\text {O-C-O }}\right) / 1406-1409$ (symv $\left.v_{\text {O-C-O }}\right)$ and 1515-1541 (asymv $v_{\text {O-C- }}$ o)/1422-1432 (symv $\left.v_{\mathrm{O}-\mathrm{C}-\mathrm{O}}\right) \mathrm{cm}^{-1}$, with $\Delta v_{3}$ between 254,184 and $85-119 \mathrm{~cm}^{-1}$, respectively, may correspond to two different unidentate structures. The first value of $\Delta v_{3}$ is higher than the above reported for unidentatespecies, nevertheless the similar thermal stability displayed by the three pairs of bands suggests that they could be originated by analogous species.

Bands around 1685 and 1660 belong to the asymmetric $v_{\mathrm{O}-\mathrm{C}-\mathrm{O}}$ vibrations of chelating bidentate carbonates, whereas the bands around1310 and 1350are attributed to their symv $v_{\mathrm{O}-\mathrm{C}-\mathrm{O}}$ modes. Finally, bands around 1730 and 1705 correspond to the asymmetric $v_{\mathrm{O}-}$ 
C-O vibrations of bridging bidentate carbonates, while the bands around1220 and 1280 are attributed to their symv $v_{\text {O-C-O }}$ modes. $\Delta v_{3}$ of 312-379 and 423-507 displayed by chelating and bridging bidentate carbonates, respectively, are in relative good agreement with the above proposed.

Regarding the thermal stability of the adsorbed species, bridging bidentate carbonates and bicarbonates are formed on the weakest basic sites, since they disappear above 323 and $373 \mathrm{~K}$, respectively. On the other hand, chelating bidentateand unidentate carbonates are still present at $573 \mathrm{~K}$. Nevertheless, while for the samples $\mathrm{MgO}(\mathrm{I})$ and hsMgO(I) no peaks were detected in the last scan, for the samples $\mathrm{MgO}$ (II) and hsMgO(II) slight evidences of remaining unidentate carbonatesare appreciated at $673 \mathrm{~K}$, which indicates the presence of stronger sites in these samples compared with $\mathrm{MgO}(\mathrm{I})$ and hsMgO(I).Therefore, unidentate carbonates correspond to the strongest basic sites found by microcalorimetry, chelating bidentate corresponds to medium strength sites, and bridgingbidentate and bicarbonates are the weakest ones. The unidentate carbonates are responsible of the irreversibility of the $\mathrm{CO}_{2}$ adsorption process [20], but the role of these sites in the catalytic reaction is still unclear.

\subsection{Reaction studies}

The gas phase condensation of acetone was performed over the four catalysts at temperatures between 373 and $723 \mathrm{~K}$. The presence of diffusional limitations was ruled out based on the Thiele modulus modified by Weisz [28]. In a previouswork [8], it was checked the negligible conversion at these conditions in absence of catalyst. According to the reaction pathway published in the literature [6,29], the condensation reaction of acetone leads to diacetone alcohol, which after a dehydration reaction forms either 
isomesityl oxide or mesityl oxide. The formation of these C6 compounds requires the presence of basic sites [30]. Further condensation of these C6 molecules with acetone form phorones (C9), which rearrange to yield cyclic C9 compounds called isophorones (the most valuable product).

The results of conversion for the four catalysts are shown in Fig. 8, whereas conversion, carbon balance and selectivities for the different products at 523 and $723 \mathrm{~K}$ are shown in Table 3.It should be noted that the formation of heavier reaction products, which can lead to catalyst deactivation in experiments performed at larger reaction times, lead to poorer carbon balance closures in the experiments performed at the highest temperature.

Acetone conversion increases with the temperature, reaching more than $37 \%$ of conversion at $723 \mathrm{~K}$ for the hsMgO(I) sample.Concerning the selectivities, at temperatures until $573 \mathrm{~K}, \mathrm{C} 6$ compounds were the main products, whereas at higher temperatures the trimers increase their concentration. The highest selectivity towards isophorones (IP) were $32.8 \%$, and for mesitylene (M), $20.7 \%$ at $723 \mathrm{~K}$ for hsMgO(I). These values are higher than those obtained previously under similar conditions: 13.9 (IP) and $3.2(\mathrm{M}) \%$ at $723 \mathrm{~K}$, in the case of Mg-Al oxides [8]; and 18 (IP) and 10 (M) \% at $575 \mathrm{~K}$ for $\mathrm{Mg}$ - $\mathrm{Zr}$ oxides [9]. What is more, comparing $\mathrm{MgO}$ results with those obtained for $\mathrm{Mg}-\mathrm{Zr}$ oxides dispersed on a high surface area graphite, it is observed that selectivities towards $\mathrm{C} 9$ compounds are slightly higher (53.8 for $\mathrm{MgO}$ versus $42 \%$ for $\mathrm{Mg}-\mathrm{Zr}$ supported catalyst).Although the conversion is lower (32.8 versus 54\%) [9], $\mathrm{MgO}$ catalyst is much cheaper.

The conversion obtained for the studied catalysts can be directly correlated to the surface area of the material, increasing the conversion with the surface area, and also to the concentration of basic sites (increasing surface areas imply higher concentration of 
active sites). This effect was already observed in the MPV reaction over MgO oxides [16]. It is remarkable that these relationships are not linear, but two marked trends are observed depending on the starting material of the catalysts, observing two similar trends for the correlation between surface area and basic sites with the conversion obtained at $723 \mathrm{~K}$ (Fig. $9 \mathrm{a}$ and b). This analogy between $\mathrm{MgO}(\mathrm{I}) / \mathrm{hsMgO}(\mathrm{I})$ and $\mathrm{MgO}(\mathrm{II}) / \mathrm{hsMgO}$ (II) can be related both to the absence of the strongest basic sites in the $\mathrm{MgO}(\mathrm{I})$-based samples, but also to the similar ratio between weak and medium strength basic sites: $\mathrm{MgO}(\mathrm{I})$ and $\mathrm{hsMgO}(\mathrm{I}), 0.34$ and 0.40 , respectively; whereas for $\mathrm{MgO}(\mathrm{II})$ and $\mathrm{hsMgO}(\mathrm{II}), 1.5$ and 0.9 , respectively.

In order to study the influence of morphology and surface chemistry on catalyst performance, results obtained can be analyzed as function of temperature. At low temperatures (up to $523 \mathrm{~K}$ ), only C6 are formed in relevant concentrations, except for the hsMgO(I). This catalyst exhibits the highest activity and C9 products are already present. For the other catalysts, diacetone alcohol follows the behaviour typical of primary products, which decompose with the increase of temperature in other compounds. Concerning the mesityl oxide and isomesityl oxide, the first one is the main product. The diacetone alcohol formation requires medium strength basic sites (aldol condensation reaction), whereas the further dehydration needs both acid-base pairs, thus add to medium, also weak basic sites favour this reaction [9]. At this point, there is a remarkable difference with the behaviour of $\mathrm{Mg}$ - $\mathrm{Zr}$ mixed oxides, the formation of diacetone alcohol as non-reactive side product being observed.

At higher temperatures, lower selectivities towards C6 compounds are observed. At 723 $\mathrm{K}$, the concentration of $\mathrm{C} 6$ compounds is enriched in isomesityl oxide. This result can be attributed to the presence of two different active sites for the diacetone dehydration, yielding either mesityl oxide or isomesityl oxide. Only the former is able to follow the 
reaction toward trimers [9]. The samples $\mathrm{MgO}(\mathrm{II})$ and hsMgO(II), with lower concentration of weak basic sites, have also lower concentration of acid-base pairs, thus being limited in this step.

Concerning the formation of trimers, the first compound is the linear trimer, only detected over the hsMgO(I), which reacts to form either isophorones or mesitylene. Isophorones, the main trimer, are formed by intramolecularaldol condensation of phorones, requiring strong basic sites. At $623 \mathrm{~K}$ (not shown), isophorones selectivity is higher for hsMgO(II), $16.1 \%$, than hsMgO(I), $15.4 \%$, in agreement with the strongest basicity of hsMgO(II). In fact, hsMgO(II) shows the highest concentration of strong basic sites and, according to FT-IR results, unidentate carbonatesremain at the highest temperature studied. However, at $723 \mathrm{~K}$,null presence of either isophorones or mesitylene is observed for hsMgO(II). Both $\mathrm{MgO}$ samples exhibit similar selectivity towards isophores $(26.1 \%)$, whereas hsMgO(I) exhibits the highest selectivity (32.8\%). Likewise, it is observed that the carbon balance at $723 \mathrm{~K}$ decreases for all catalysts, and this trend is more notorious in the case of hsMgO(II). Thus, further reactions not detected could occur on the surface of this catalyst consuming the C9 compounds. These condensation products could be adsorbed on the strongest basic sites (by analogy with the adsorption of $\mathrm{CO}_{2}$ ), hindering further reaction and limiting the formation of mesityl oxide.

\section{CONCLUSIONS}

The effect of the preparation procedure of magnesium oxide (precursor and hydrothermal treatment)has been studied for the condensation of acetone. Calorimetry 
measurements, as well as FT-IR analysis, were used to understand the modifications of the surface chemistry.

The thermal decomposition procedure generates defects in the surface that are responsible for its high surface area $\left(221 \mathrm{~m}^{2} / \mathrm{g}\right)$. and important concentration of surface basic sites. Furthermore, it was shown that high surface area $\mathrm{MgO}$ prepared by this methodology is an effective catalyst for the aldol condensation of acetone, reaching conversion similar to mixed oxides and selectivities towards the isophorones, even higher than for these materials.

\section{ACKNOWLEDGEMENTS}

This work was supported by the Spanish Government (contractMICINN-12-CTQ201129272-C04-02). M. León and L. Faba thank the Government of the Principality of Asturias for the Ph.D. fellowships (Severo Ochoa Program). Jorge Quesada is acknowledged by his cooperation in the reaction studies.

\section{REFERENCES}

[1] G.W. Huber, S. Iborra, A. Corma, Chem. Rev. 106 (2006) 4044

[2] J.C. Serrano-Ruiz, D.J. Braden, R.M. West, J.A. Dumesic, Appl. Catal. B 100 (2010) 184.

[3] E.L. Kunkes, D.A. Simonetti, R.M. West, J.C. Serrano-Ruiz, C.A. Gärtner, J.A. Dumesic, Science (2008) 417.

[4] D. Mansur, T. Yoskikama, K. Norinaga, J. Hayashi, T. Tago, T. Masuda, Fuel 103 (2013) 130.

[5] N. Qureshi, T. Ezeji, BiofuelBioprod. Bior. 2 (2008) 319.

[6] M. Paulis, M. Martín, D.B. Soria, A. Díaz, J.A. Odriozola, M. Montes, Appl. Catal. A 180 (1999) 411.

[7] A.A. Nikolopoulos, B.W.-L. Jang, J.J. Spivey, Appl. Catal. A 296 (2005) 128. 
[8] S. Ordóñez, E. Díaz, M. León, L. Faba, Catal. Today 167 (2011) 71.

[9] L. Faba, E. Díaz, S. Ordóñez, Appl. Catal. B 142-143 (2013) 387.

[10] J.I. Di Cosimo, V.K Díez, C.R. Apesteguía, Appl. Catal. A 137 (1996) 149-

166.

[11] M. Bhagiyalakshmi, J.Y. Lee, H.T. Jang, Int. J. Greenh. Gas Con. 4 (2010) 51.

[12] S. Utamapanya, K.J.Klabunde, J.R.Schlup, Chem. Mater. 3 (1991) 175.

[13] J. Roggenbuck, M.Tiemann, J. Am. Chem. Soc. 127(2005) 1096.

[14] D. Gulková, O. Šolcová, M. Zdražil, MicroporousMesoporous Mater. 76(2004) 137.

[15] S.W. Bian, J.Baltrusaitis, P. Galhotra, V.H. Grassian, J. Mater. Chem. 20 (2010) 8705 .

[16] J.K. Bartley, C. Xu, R. Lloyd, D.I. Enache, D.W. Knight, G.J. Hutchings, Appl. Catal. B 128 (2012) 31.

[17] R. Jenkins, R.L. Snyder, Introduction to X-ray Powder Diffractometry, John Wiley \& Sons Inc, New York, 1996.

[18] M. León, E. Díaz, A. Vega, S. Ordóñez, Chem. Eng. J. 175 (2011) 341.

[19] J.A. Wang, O.Novaro, X. Bokhimi, T. López, R. Gómez, J. Navarrete, M.E. Llanos, E. López-Salinas, Mater. Lett. 35 (1998) 317.

[20] M. León, E. Díaz, S. Bennici, A. Vega, S. Ordóñez, A. Auroux, Ind. Eng. Chem. Res. 49 (2010) 3663.

[21] J.T. Kozlowski, R.J. Davis, J. Energy Chem. 22 (2013) 58.

[22] A. Auroux, Top. Catal. 4 (1997) 71.

[23] A. Auroux, R. Monaci, E. Rombi, V. Solinas, A. Sorrentino, E.

Santacesaria,Thermochim. Acta 379 (2001) 227.

[24] D. Meloni, R. Monaci, V. Solinas, A. Auroux, E.Dumitriu,Appl. Catal. A 350 (2008) 86.

[25] M. León, E. Díaz, A. Vega, S. Ordóñez, A. Auroux, Appl. Catal. B 102 (2011)

590.

[26] G. Ramis, G. Busca, V. Lorenzelli, Mater. Chem. Phys. 29 (1991) 425.

[27] F. Prinetto, G. Ghiotti, R. Durand, D. Tichit, J. Phys. Chem. B 104 (2000) 11117.

[28] P.B. Weisz, Science 179 (1973) 433.

[29] P. Kustrowski, D. Sułkowska, L.Chmielarz, A.Rafalska-Łasocha, B.Dudek, R.Dziembaj, MicroporousMesoporous Mater. 78 (2005) 11.

[30] J.I. Di Cossimo, V.K. Díez, M. Xu, E. Iglesia, C.R. Apesteguia, J. Catal. 178 (1998) 499. 
Table 1.Textural properties of the different magnesium oxides tested in this work.

\begin{tabular}{llll}
\hline Sample & $\mathrm{S}_{\mathrm{BET}}\left(\mathrm{m}^{2} / \mathrm{g}\right)$ & $\begin{array}{l}\mathrm{V}_{\mathrm{p}, \text { mesopores }} \\
\left(\mathrm{cm}^{3} / \mathrm{g}\right)\end{array}$ & $\mathrm{L}_{200}(\mathrm{~nm})$ \\
\hline $\mathrm{MgO}(\mathrm{I})$ & 26 & - & 56.9 \\
$\mathrm{MgO}(\mathrm{II})$ & 70 & 0.189 & 7.2 \\
$\mathrm{hsMgO}(\mathrm{I})$ & 221 & 1.147 & 11.0 \\
hsMgO(II) & 87 & 0.530 & 8.7 \\
\hline
\end{tabular}

$\mathrm{S}_{\mathrm{BET}}$ : surface area obtained by nitrogen adsorption-desorption isotherms by the Brunauer-Emmett-Teller theory.

$\mathrm{V}_{\mathrm{p}}$ : pore volume corresponding to the cumulative pore volumes between 170 and $30000 \mathrm{~nm}$, determined from the desorption branch using the Barrett-Joyner-Halenda (BJH) method

$\mathrm{L}_{200}$ : crystallite size of the oxides calculated from the plane (200) of $\mathrm{MgO}$ using the Debye-Scherrer equation. 
Table 2. Characteristic bands of the species formed upon $\mathrm{CO}_{2}$ adsorption on the magnesium oxides

\begin{tabular}{|c|c|c|c|c|c|c|c|c|c|c|c|c|c|c|c|}
\hline & $\mathrm{bb}$ & $\mathrm{bb}$ & $\mathrm{h} / \mathrm{cb}$ & $\mathrm{cb}$ & $\mathrm{u}$ & $\mathrm{u}$ & $\mathrm{u}$ & $\mathrm{h}$ & $\mathrm{u}$ & $\mathrm{u}$ & $\mathrm{u}$ & $\mathrm{cb}$ & $\mathrm{cb}$ & $\mathrm{bb}$ & $\mathrm{h} / \mathrm{bb}$ \\
\hline $\mathrm{MgO}(\mathrm{I})$ & & $\begin{array}{l}\mathbf{1 7 0 6} \\
(4)\end{array}$ & $\begin{array}{l}\mathbf{1 6 8 5} \\
(4) \\
{[379]}\end{array}$ & $\begin{array}{l}\mathbf{1 6 6 2} \\
(3) \\
{[313]}\end{array}$ & $\begin{array}{l}\mathbf{1 6 3 5} \\
(6) \\
{[254]}\end{array}$ & $\begin{array}{l}\mathbf{1 5 9 4} \\
(9) \\
{[184]}\end{array}$ & $\begin{array}{l}\mathbf{1 5 1 7} \\
(9) \\
{[85]}\end{array}$ & & $\begin{array}{l}1432 \\
(5)\end{array}$ & $\begin{array}{l}\mathbf{1 4 0 9} \\
(6)\end{array}$ & $\begin{array}{l}\mathbf{1 3 8 2} \\
(2)\end{array}$ & $\begin{array}{l}1349 \\
(4)\end{array}$ & $\begin{array}{l}\mathbf{1 3 0 6} \\
(8)\end{array}$ & & $\begin{array}{l}\mathbf{1 2 2 0} \\
(1)\end{array}$ \\
\hline $\mathrm{MgO}(\mathrm{II})$ & $\begin{array}{l}\mathbf{1 7 2 6} \\
(10) \\
{[507]}\end{array}$ & $\begin{array}{l}\mathbf{1 7 0 6} \\
(16) \\
{[417]}\end{array}$ & $\begin{array}{l}\mathbf{1 6 8 6} \\
(18) \\
{[375]}\end{array}$ & $\begin{array}{l}\mathbf{1 6 6 5} \\
(13) \\
{[316]}\end{array}$ & $\begin{array}{l}\mathbf{1 6 4 0} \\
(32) \\
{[254]}\end{array}$ & $\begin{array}{l}\mathbf{1 6 0 3} \\
(31)\end{array}$ & $\begin{array}{l}\mathbf{1 5 4 1} \\
(41) \\
{[119]}\end{array}$ & $\begin{array}{l}\mathbf{1 4 5 8} \\
(9)\end{array}$ & $\begin{array}{l}\mathbf{1 4 2 2} \\
(22)\end{array}$ & & $\begin{array}{l}\mathbf{1 3 8 6} \\
(23)\end{array}$ & $\begin{array}{l}\mathbf{1 3 4 9} \\
(25)\end{array}$ & $\begin{array}{l}\mathbf{1 3 1 1} \\
(18)\end{array}$ & $\begin{array}{l}\mathbf{1 2 8 9} \\
(21)\end{array}$ & $\begin{array}{l}\mathbf{1 2 2 0} \\
(10)\end{array}$ \\
\hline hsMgO(I) & $\begin{array}{l}\mathbf{1 7 3 1} \\
(7) \\
{[513]}\end{array}$ & $\begin{array}{l}\mathbf{1 7 0 4} \\
(11) \\
{[427]}\end{array}$ & $\begin{array}{l}\mathbf{1 6 8 3} \\
(13) \\
{[377]}\end{array}$ & $\begin{array}{l}\mathbf{1 6 6 2} \\
(10) \\
{[314]}\end{array}$ & $\begin{array}{l}\mathbf{1 6 3 3} \\
(30) \\
{[250]}\end{array}$ & $\begin{array}{l}\mathbf{1 5 9 1} \\
(18) \\
{[184]}\end{array}$ & $\begin{array}{l}\mathbf{1 5 3 8} \\
(14) \\
{[109]}\end{array}$ & $\begin{array}{l}\mathbf{1 4 5 7} \\
(5)\end{array}$ & $\begin{array}{l}1429 \\
(5)\end{array}$ & $\begin{array}{l}1406 \\
(4)\end{array}$ & $\begin{array}{l}\mathbf{1 3 8 3} \\
(12)\end{array}$ & $\begin{array}{l}\mathbf{1 3 4 7} \\
(12)\end{array}$ & $\begin{array}{l}\mathbf{1 3 0 6} \\
(15)\end{array}$ & $\begin{array}{l}\mathbf{1 2 7 7} \\
(6)\end{array}$ & $\begin{array}{l}1218 \\
(5)\end{array}$ \\
\hline hsMgO(II) & $\begin{array}{l}\mathbf{1 7 2 7} \\
(10) \\
{[507]}\end{array}$ & $\begin{array}{l}\mathbf{1 7 0 6} \\
(7) \\
{[423]}\end{array}$ & $\begin{array}{l}\mathbf{1 6 8 5} \\
(20) \\
{[374]}\end{array}$ & $\begin{array}{l}\mathbf{1 6 6 1} \\
(15) \\
{[312]}\end{array}$ & $\begin{array}{l}\mathbf{1 6 3 5} \\
(23) \\
{[254]}\end{array}$ & $\begin{array}{l}\mathbf{1 5 9 0} \\
(42) \\
{[184]}\end{array}$ & $\begin{array}{l}\mathbf{1 5 1 5} \\
(25) \\
{[87]}\end{array}$ & $\begin{array}{l}\mathbf{1 4 5 6} \\
(13)\end{array}$ & $\begin{array}{l}\mathbf{1 4 2 8} \\
(13)\end{array}$ & $\begin{array}{l}\mathbf{1 4 0 6} \\
(13)\end{array}$ & $\begin{array}{l}\mathbf{1 3 8 1} \\
(22)\end{array}$ & $\begin{array}{l}\mathbf{1 3 4 9} \\
(10)\end{array}$ & $\begin{array}{l}\mathbf{1 3 1 1} \\
(20)\end{array}$ & $\begin{array}{l}\mathbf{1 2 8 3} \\
(11)\end{array}$ & $\begin{array}{l}\mathbf{1 2 2 0} \\
(8)\end{array}$ \\
\hline
\end{tabular}

$u$ (unidentate carbonates), $c b$ (chelating bidentate carbonates), $b b$ (bridged bidentate carbonates), and $h$ (bicarbonates).

In bold $\left(\mathrm{cm}^{-1}\right)$ :Infrared bands after $\mathrm{CO}_{2}$ adsorption at room temperature

In brackets:area of the decomposed peaks

In square brackets: $\Delta v_{3}$ values $\left(\mathrm{cm}^{-1}\right)$ 
Table 3. Evolution of selectivity of acetone condensation towards the reactions products at twotemperatures: diacetone alcohol (DAA), isomesityl oxide (IMO), mesityl oxide (MO), phorone (P), mesitylene (M) and isophorone (IP)

\begin{tabular}{|c|c|c|c|c|c|c|c|c|c|c|c|c|c|c|}
\hline \multirow[t]{3}{*}{ Catalyst } & \multirow{2}{*}{\multicolumn{2}{|c|}{$\begin{array}{l}\text { Conversion }(\%) / \\
\text { carbon balance } \\
(\%)\end{array}$}} & \multicolumn{12}{|c|}{ Selectivity (\%) } \\
\hline & & & \multicolumn{2}{|c|}{$\begin{array}{l}\text { Diacetone } \\
\text { alcohol }\end{array}$} & \multicolumn{2}{|c|}{$\begin{array}{l}\text { Isomesityl } \\
\text { oxide }\end{array}$} & \multicolumn{2}{|c|}{ Mesityl oxide } & \multicolumn{2}{|c|}{ Phorone } & \multicolumn{2}{|c|}{ Mesitylene } & \multicolumn{2}{|c|}{ Isophorone } \\
\hline & $523 \mathrm{~K}$ & $723 \mathrm{~K}$ & $523 \mathrm{~K}$ & $723 \mathrm{~K}$ & $523 \mathrm{~K}$ & $723 \mathrm{~K}$ & $523 \mathrm{~K}$ & $723 \mathrm{~K}$ & $523 \mathrm{~K}$ & $723 \mathrm{~K}$ & $523 \mathrm{~K}$ & $723 \mathrm{~K}$ & $523 \mathrm{~K}$ & $723 \mathrm{~K}$ \\
\hline $\mathrm{MgO}$ (I) & $20.0 / 88.9$ & $22.7 / 95.6$ & 5.1 & 0.7 & 15.1 & 58.7 & 79.7 & 3.2 & 0 & 0 & 0.1 & 11.3 & 0 & 26.1 \\
\hline $\mathrm{MgO}$ (II) & $17.8 / 88.3$ & $19.7 / 92.9$ & 5.1 & 0.7 & 15.1 & 58.7 & 79.8 & 3.3 & 0 & 0 & 0 & 11.2 & 0 & 26.1 \\
\hline hsMgO (I) & $33.0 / 72.9$ & $37.0 / 85.2$ & 0 & 0.2 & 7.2 & 9.3 & 49.4 & 33.8 & 10.9 & 3.2 & 10.6 & 20.7 & 21.9 & 32.8 \\
\hline hsMgO (II) & $25.6 / 72.9$ & $28.9 / 81.6$ & 14.6 & 0.0 & 0 & 28.7 & 85.4 & 71.3 & 0 & 0 & 0 & 0 & 0 & 0 \\
\hline
\end{tabular}


Scheme 1.Activation steps and notation (bold) used in this work for the different $\mathrm{MgO}$ used in this work

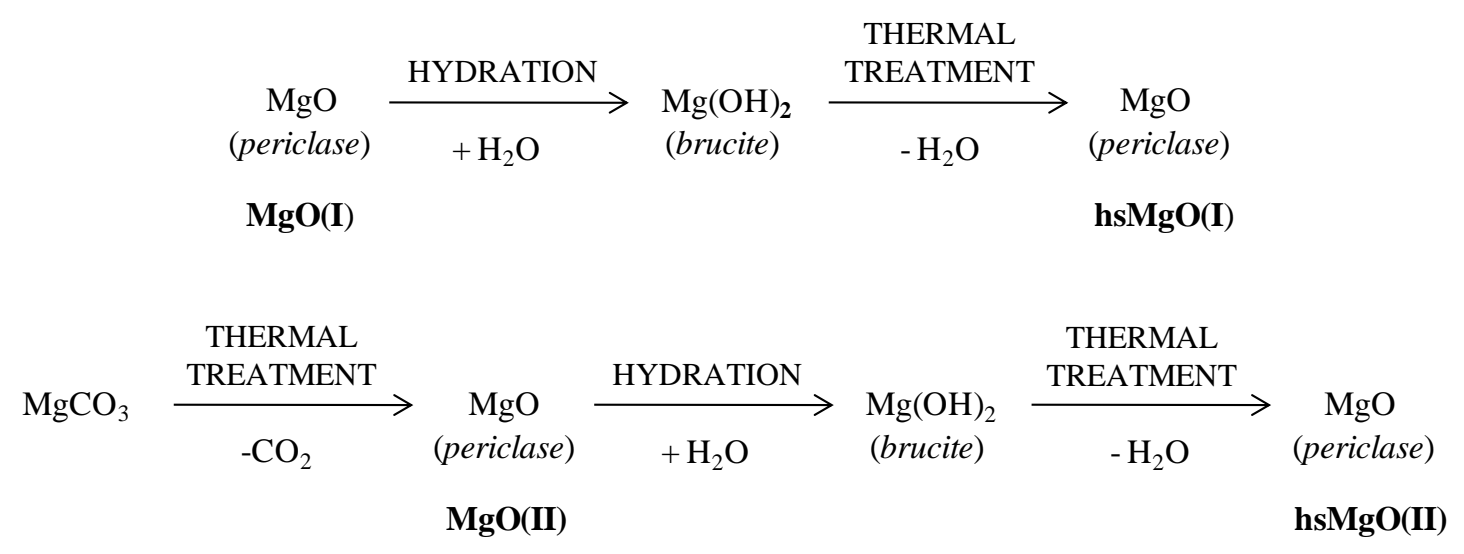

Scheme 2.Species formed upon $\mathrm{CO}_{2}$ adsorption<smiles>O=[M]OC(=O)O</smiles>

Unidentate

carbonate<smiles>[M]O[O+]1OC1=O</smiles>

Chelating bidentate carbonate<smiles></smiles><smiles>[M]OC(=O)O</smiles>

Bridging bidentate carbonate
Bicarbonate 


\section{FIGURE CAPTIONS:}

Fig. 1.XRD patterns corresponding tothe magnesium oxides: $\mathrm{MgO}(\mathrm{I}), \mathrm{MgO}(\mathrm{II})$, hsMgO(I) and hsMgO(II)

Fig. 2.XRD patterns corresponding to the transition brucite-periclase at increasing temperature on magnesium hydroxides obtained from $\mathrm{MgO}$ (I) (a) and $\mathrm{MgO}$ (II) (b)

Fig. 3. Kinetic data corresponding to the transition brucite-periclasa $\left(\mathrm{A} / \mathrm{A}_{0}\right.$ : ratio of the area under the peak at a given time to the area under the peak at time zero)

Fig. 4. $\mathrm{N}_{2}$ adsorption-desorption isotherms at $77 \mathrm{~K}$ for the MgOsamples studied in this work.

Fig. 5. SEM images of $\mathrm{MgO}$ (I) (a), $\mathrm{MgO}$ (II) (b), hsMgO(I) (c), and hsMgO(II) (d)

Fig. 6. $\mathrm{CO}_{2}$ adsorption isotherms at $323 \mathrm{~K}$ and $6.7 \mathrm{kPa}$, measured by microcalorimetry for: $\mathrm{MgO}(\mathrm{I})(\bullet), \mathrm{MgO}(\mathrm{II})(\bullet), \mathrm{hsMgO}(\mathrm{I})$ ( $\square$ ), and hsMgO(II) (०)

Fig.7.Differential heats of $\mathrm{CO}_{2}$ adsorption vs. coverage at $323 \mathrm{~K}$ on: $\mathrm{MgO}(\mathrm{I})(\bullet)$,

$\mathrm{MgO}(\mathrm{II})$ (๘), hsMgO(I) (口), and hsMgO(II) (०). Distribution of interaction strengths of carbon dioxide adsorption on the samples: $210>\mathrm{Q}>150 \mathrm{~kJ} / \mathrm{mol}$ (black); $150>\mathrm{Q}>90$ $\mathrm{kJ} / \mathrm{mol}$ (grey); $90>\mathrm{Q}>30 \mathrm{~kJ} / \mathrm{mol}$ (white).

Fig. 8. Activity for the acetone condensation over the different $\mathrm{MgO}$ catalysts: $\mathrm{MgO}(\mathrm{I})$ (•), $\mathrm{MgO}(\mathrm{II})(\mathbf{\bullet}), \mathrm{hsMgO}(\mathrm{I})$ (口), and hsMgO(II) (०)

Fig. 9.Influence of surface area (a) and total concentration of basic sites (b) (measured by calorimetry) on the conversion of the studied catalysts at $723 \mathrm{~K}$ 


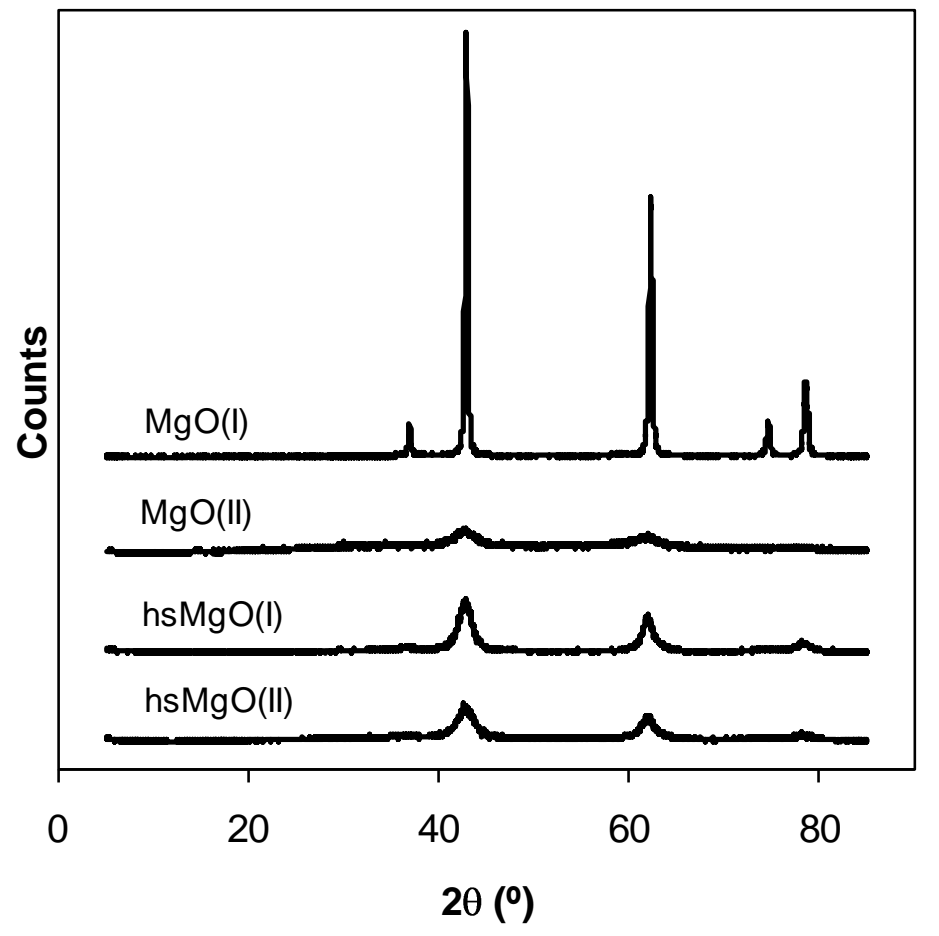

Fig. 1 
(a)

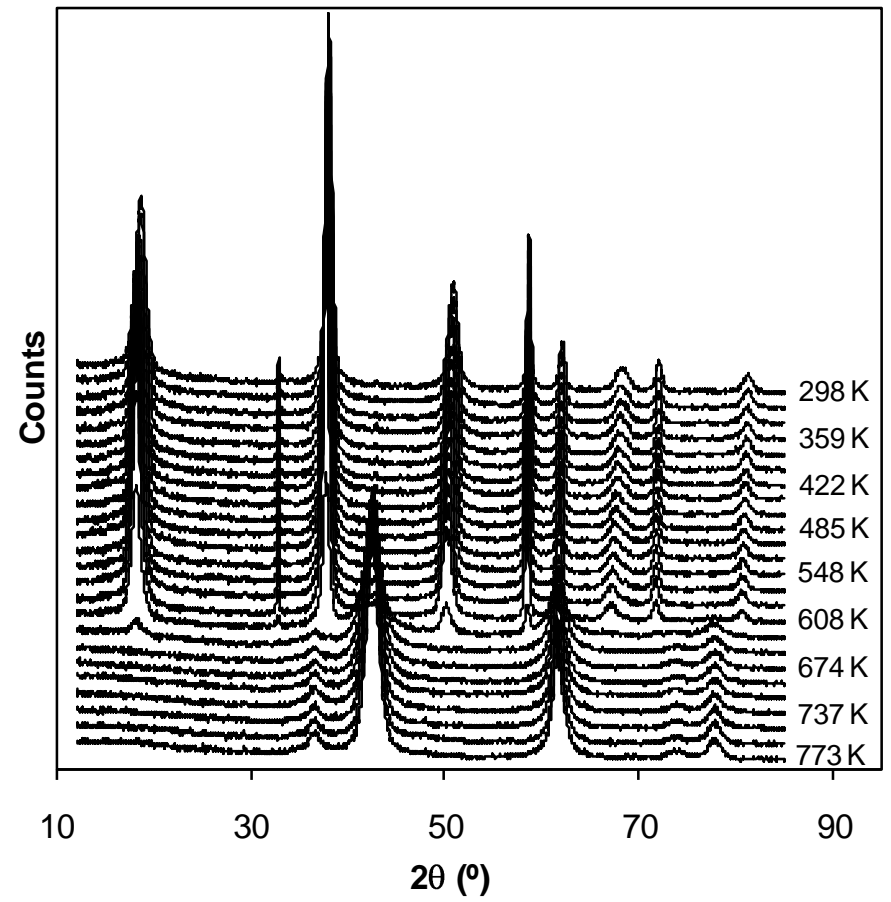

(b)

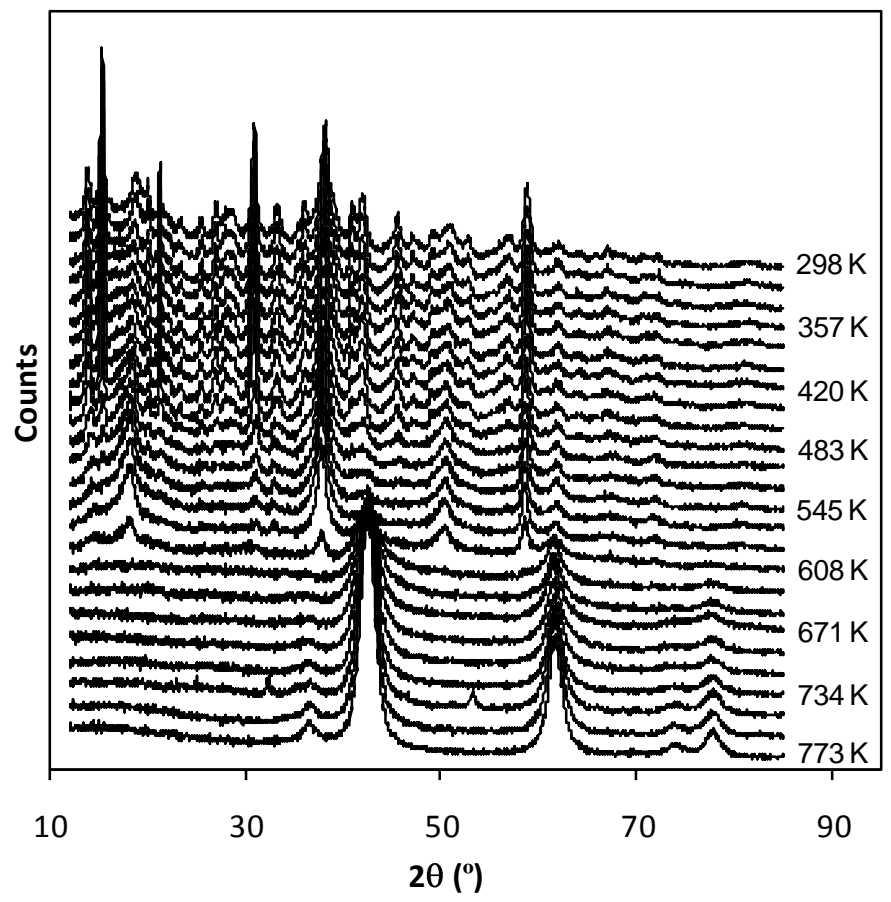

Fig. 2 


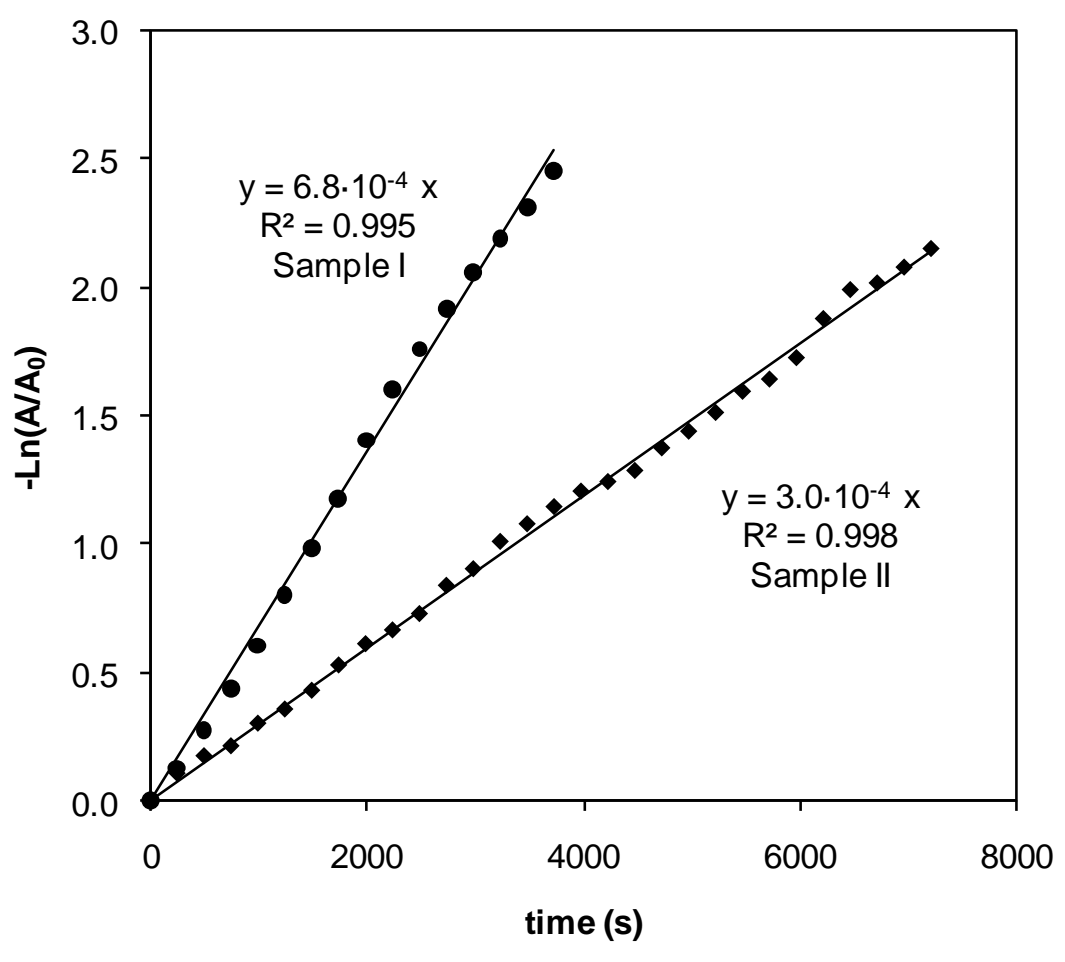

Fig. 3 


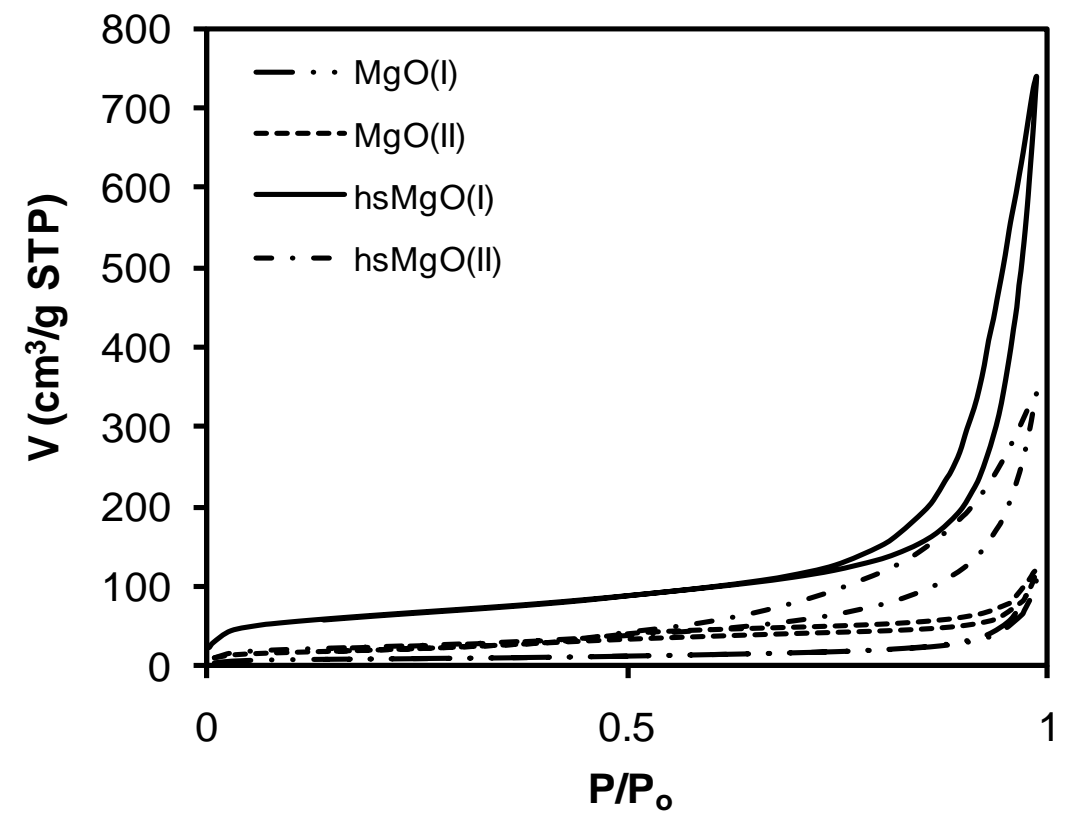

Fig. 4 

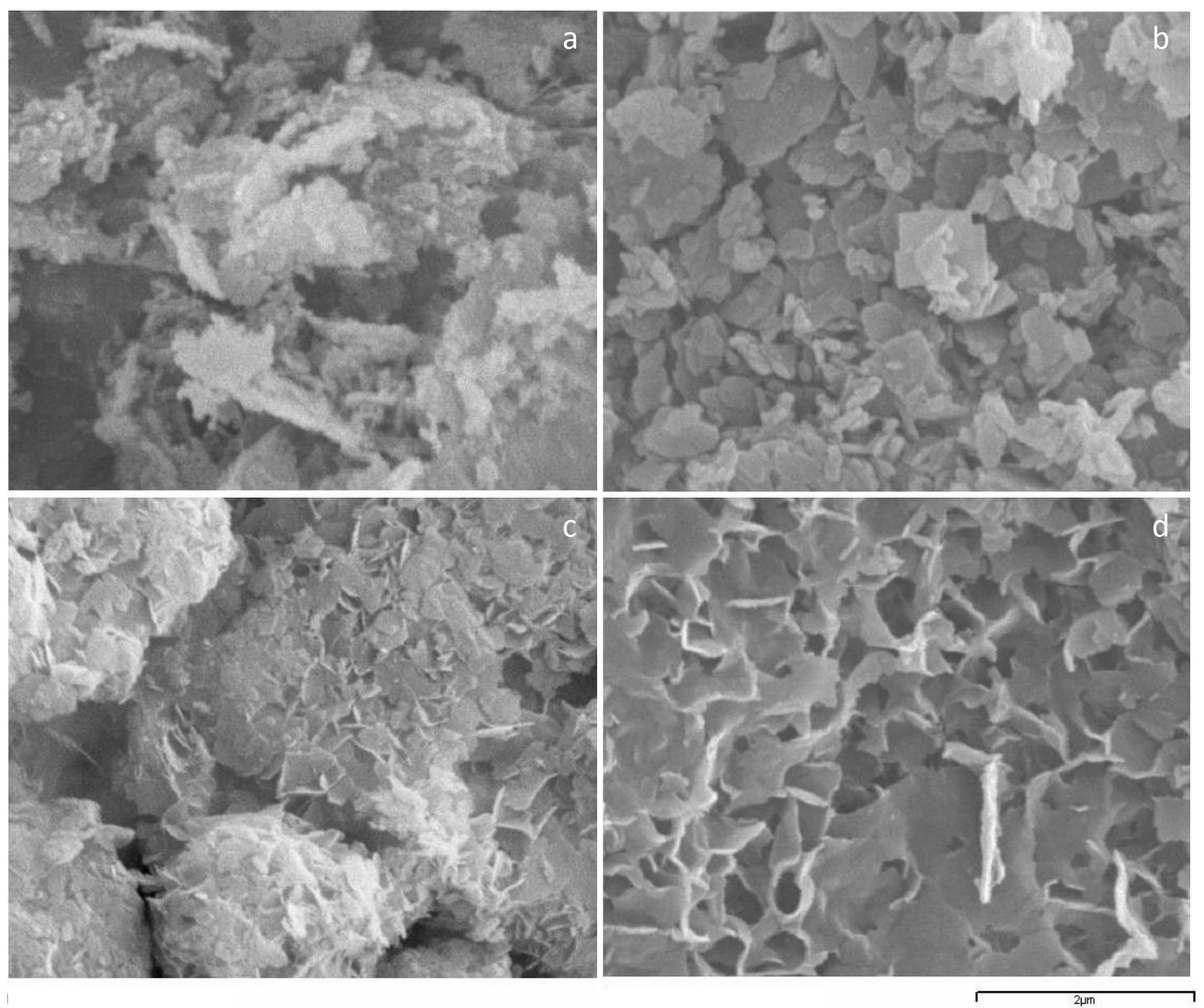

Fig. 5 


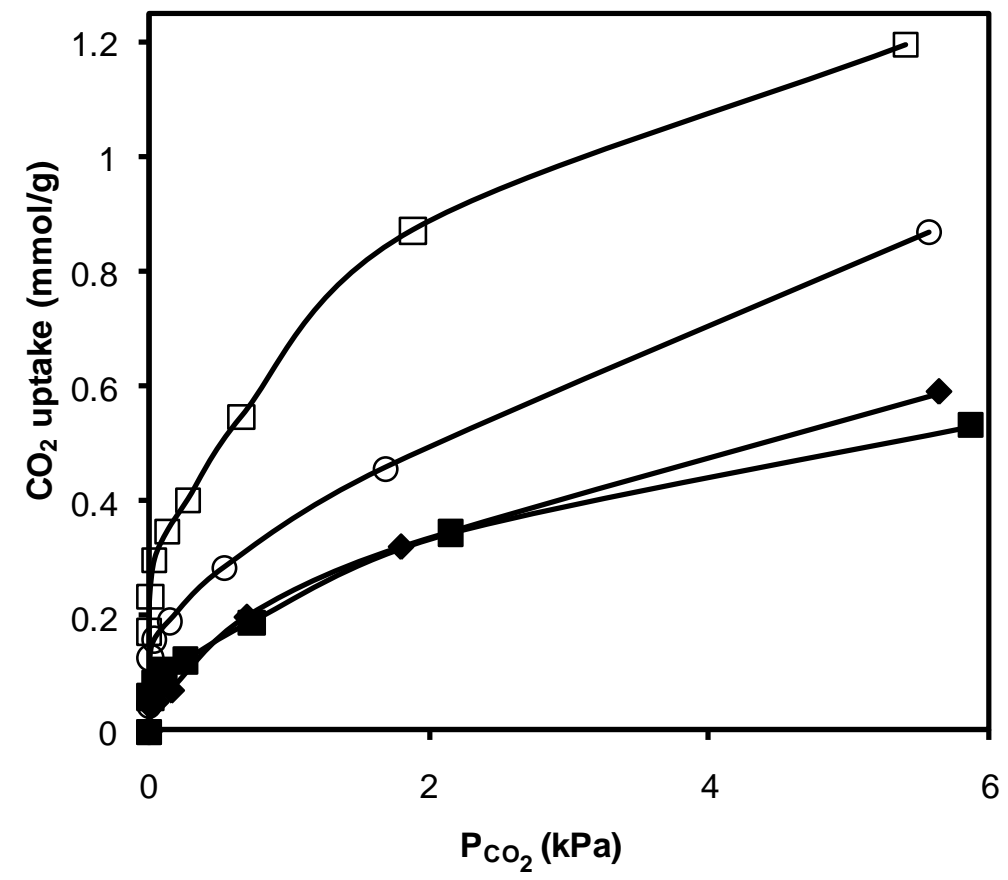

Fig. 6 


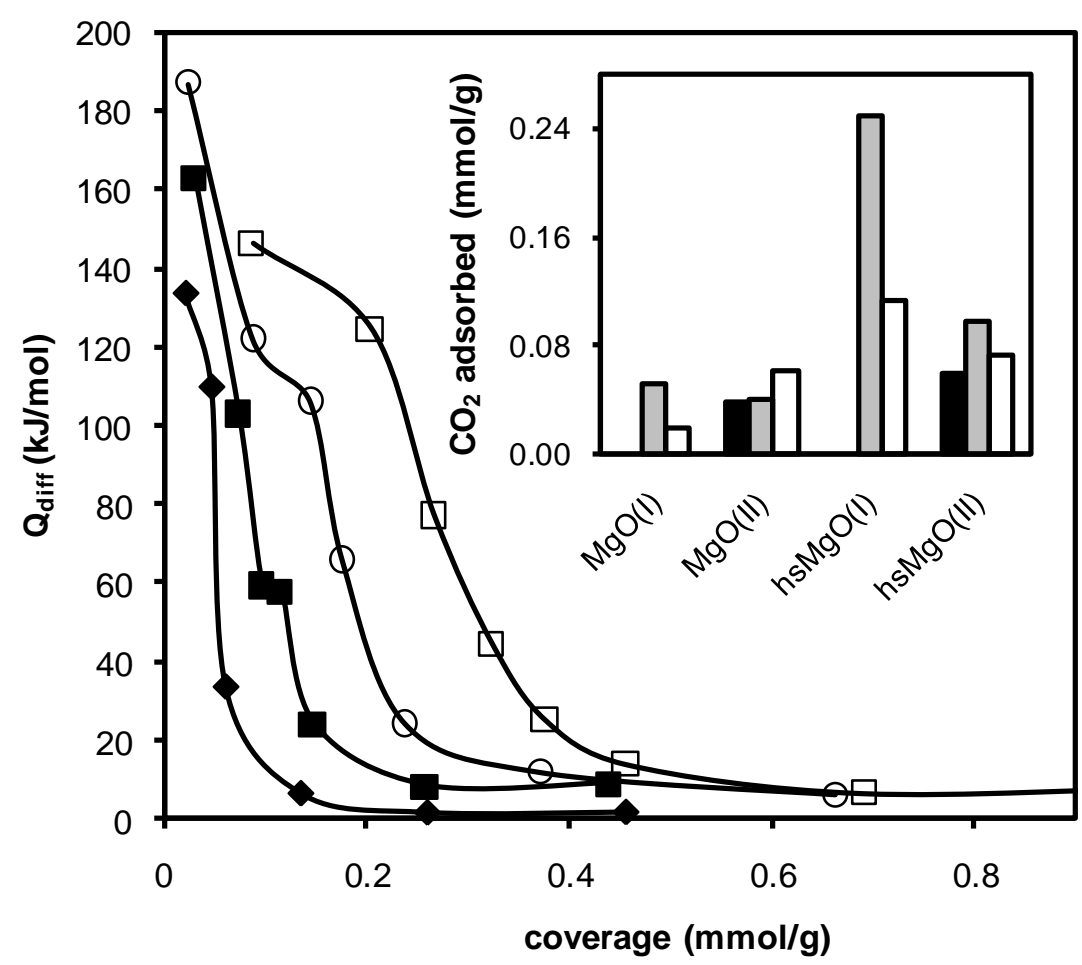

Fig. 7 


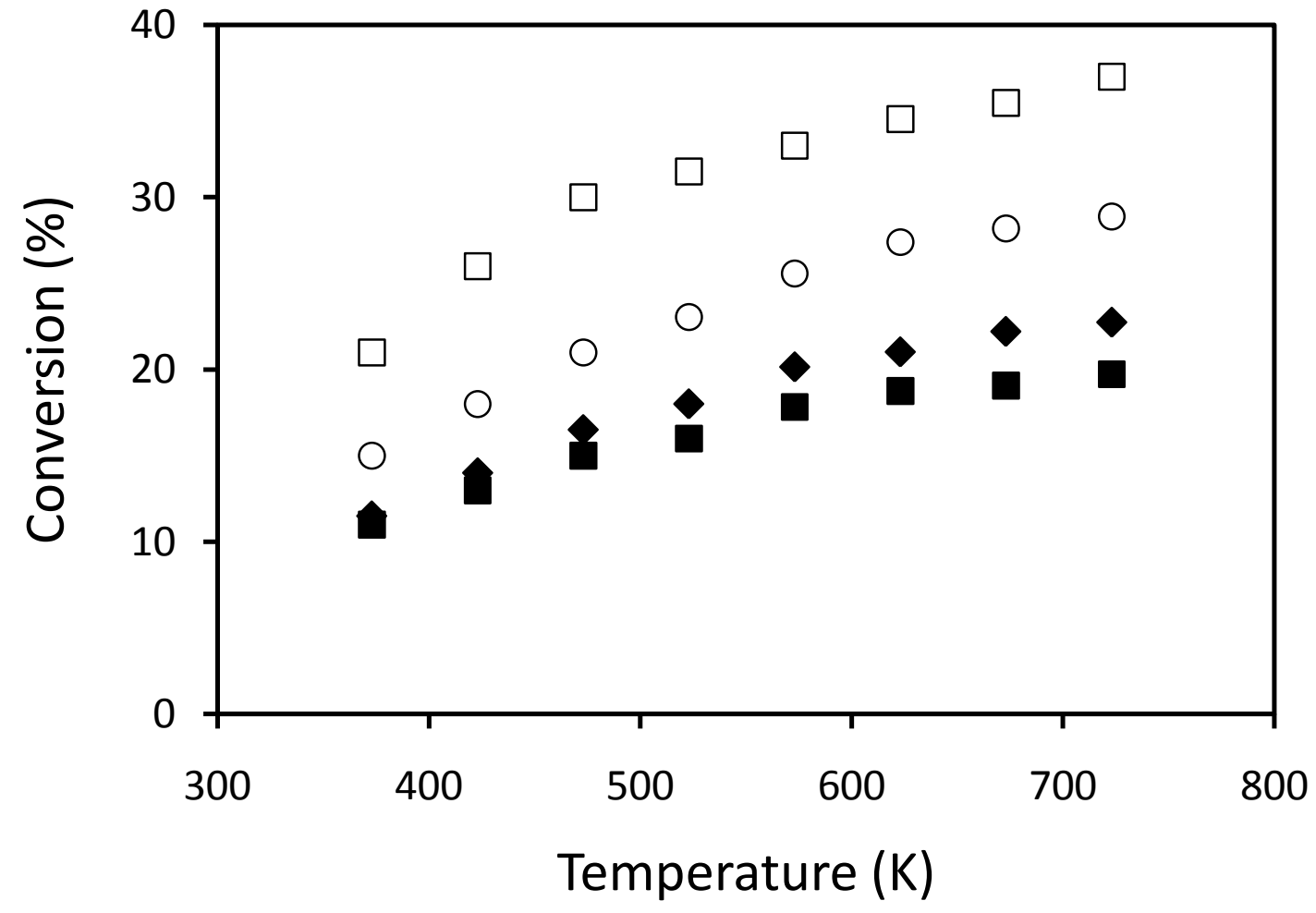

Fig. 8 


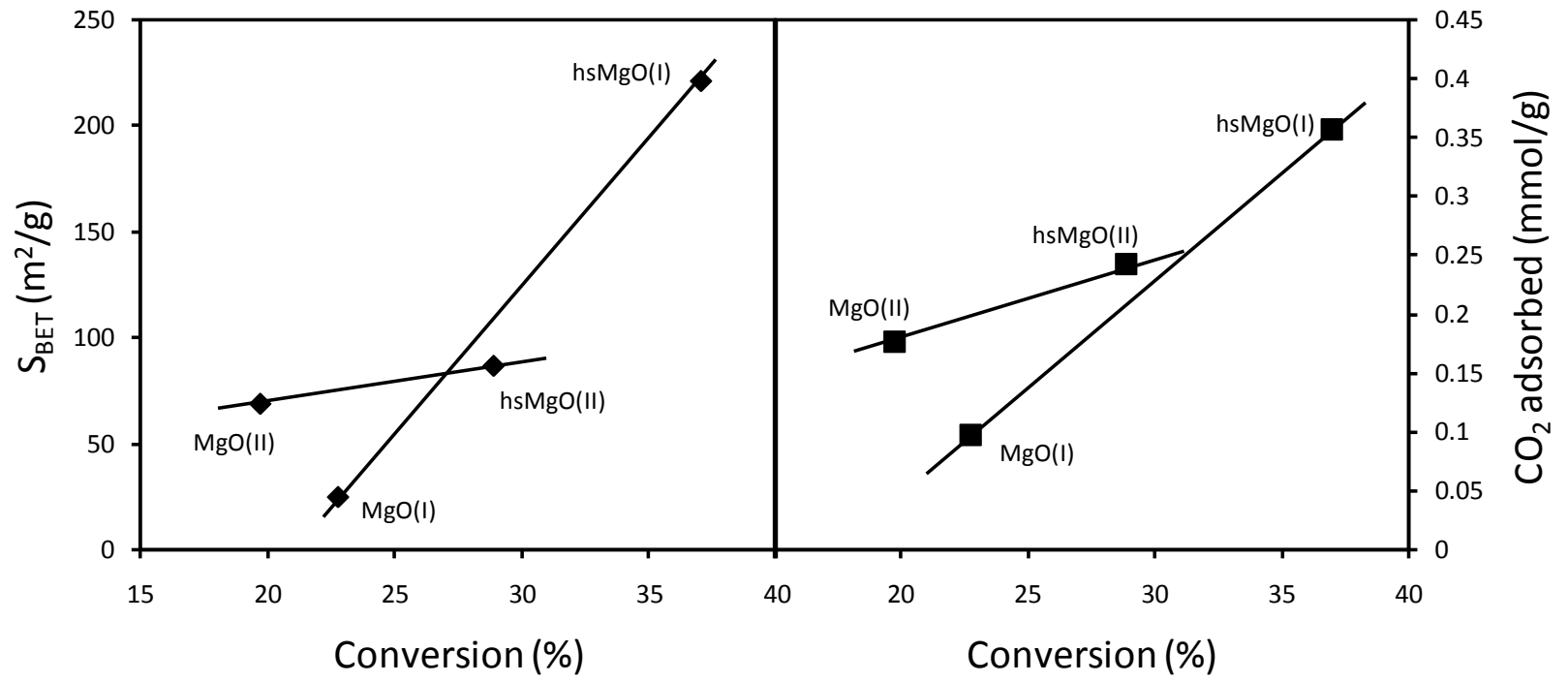

Fig. 9 